\title{
Shear deformability characteristics of a rapid-cure woven prepreg fabric
}

\author{
M. A. Khan ${ }^{1}$ (D) $\cdot$ C. Pasco ${ }^{1} \cdot$ N. Reynolds ${ }^{1} \cdot K^{\text {K. Kendall }}{ }^{1}$
}

Received: 5 September 2019 / Accepted: 10 December 2019 / Published online: 6 January 2020

(C) The Author(s) 2020

\begin{abstract}
Formability of a continuous fiber-reinforced material is known to be influenced by its intraply shear behavior. This study investigates a $2 \times 2$ twill weave carbon fabric and the corresponding vinyl-based thermoset prepreg developed for press-cured structural parts. Intraply shear tests of bias-extension and picture-frame were conducted for a range of industrial-relevant processing conditions of temperature and shear rate. The dry fabric was characterized similar to the prepreg to isolate the influence of semi-cured resin on the woven prepreg fabric formability in shear. The shear deformation behavior of the prepreg, usually dependent on the fabric architecture, is found to be controlled by the state of the resin. The results clearly show the significance of the choice of process parameters on the prepreg shear behavior. It is demonstrated that preheating the prepreg to temperatures considerably lower than required to initiate cure can make the shear formability of the woven prepreg equivalent to the constituent (dry) reinforcement fabric. The actual shear angle measurement during the bias-extension tests demonstrates the level of inter-tow slippage for the prepreg fabric at relatively elevated temperatures. The comparison of normalized shear data from the two test methods helps to determine the improved procedure for prepreg fabric testing.
\end{abstract}

Keywords Rapid-cure prepreg $\cdot$ Woven fabric $\cdot$ Intraply shear $\cdot$ Shear-angle measurement $\cdot$ Formability

\section{Introduction}

Rapid-cure thermoset prepregs are being widely used in automotive structures to achieve lightweight solutions and contribute to reduce the overall manufacturing time [1-3]. However, the automotive sector still lacks high-volume manufacturing processes with short production cycle-times to compensate the high material costs. The existing manufacturing processes for continuous fiber-reinforced materials partially meet the challenges of automotive sector up to medium range of production volumes [4]. These processes involve significant level of automation at different manufacturing stages to achieve acceptable level of efficiency and repeatability. Preforming stage involves shaping a flat laminate of plies into a threedimensional form that is generally identified as a critical step to influence the overall production cycle time and quality of

M. A. Khan

m.a.khan@warwick.ac.uk

1 WMG, The University of Warwick, Lord Bhattacharya Road, Coventry CV4 7AL, UK the composite parts. During preforming, the fabric reinforced material shears to take the shape of molds. The automotive components, being smaller in size but often complex in geometry, makes it more challenging to reliably predict the deformation behavior of materials through preforming simulation, again largely dependent upon accurate properties of the material.

Inplane shear properties of the prepregs and fabrics are measured to characterize their shear formability and used as an important material input data for forming simulations [5-9]. Inplane shear behavior of woven reinforcements is characterized by the relative rotation between warp and weft tows. Upon deformation, the initially orthogonal tows rotate relatively to each other around their crossover points resulting in a change of relative tow angle called shear angle. This particular shearing mechanism gives woven reinforcements the ability to be shaped over doublycurved surfaces without forming folds or wrinkles and is often conceptualized using the analytical approach known as the pin-jointed net (PJN) $[9,10]$. The PJN model assumes that the warp and weft tows are inextensible and are free to rotate at their crossover points (i.e. as if they are pinned) without a relative slippage. 
The shear behavior of dry fabrics and prepregs is characterized using the well-known inplane shear tests of picture frame and bias extension [10-16]. Despite the inherent drawbacks and delicacy of implementation, the two test methods are equally popular for measuring the shear properties of biaxial fabrics. The picture frame test is considered to create a uniform shear deformation of the entire specimen $[10,11,16$, 17]. This deformation mode makes the post-test analysis relatively straightforward. However, the accuracy of test data is significantly influenced by the alignment of tows in the specimen $[14,15]$. In contrast, the bias extension test is relatively insensitive to misalignment issues but it creates non-uniform deformation across the test specimen which imposes a challenge to extract the actual shear behavior from the test data. The bias extension test also induces inter-tow slip, between warp and weft tows in the plane of the specimen, especially in the case of dry fabrics and prepregs at higher temperatures as they deform to relatively higher shear angles [11-13]. Being uncontrolled, unquantified and problematic to simulate, such intraply slip limits the exploration towards maximum shear angle as well as the correct shear behavior when using the bias extension test.

The higher-rate of production requirements as well as the complex geometries of automotive structures makes it more challenging to produce high quality components from continuous fiber reinforced materials than any other sector. In the context of exploiting automation in compression molding of thermoset prepregs to meet the production rate challenges, the preforming stage induces high-deformation rates in the material. The knowledge of material deformation behavior at strain-rates and temperatures compatible to the processing of thermoset prepregs for high-volume applications can help improve the product development cycle. Typically, the processing conditions of thermoplastics involves heating the prepreg up to the melting temperature $[6,14,18]$. In contrast, preheating of thermoset prepregs prior to preforming has to be restricted below the initiation of cure recommended by the material manufacturer $[1,7,10,19]$. The preheating of prepreg softens the matrix material, promoting preforming thereby assisting the in-plane (intra/inter-ply) deformation of plies [20-24].

The actual measurement of shear angles in the case of bias extension tests is recommended due other (non-shear) deformation mechanisms occurring within the central zone of the fabric specimen where the tows are free from tension due to inherent boundary conditions [10-13]. This phenomenon is more predominant at relatively higher shear angle values. Therefore, for accurate characterization of the shear behavior of a fabric, it is important to employ an external shear angle measurement approach such as an optical strain measurement. Pasco et al. also observed this disadvantage of bias extension test in the case of woven prepreg at higher temperatures. A further challenge in the external measurement of shear angles for thermoset prepregs is the significant deformation of the speckle pattern and the loss of data correlation. Thus, a discrete method of shear angle measurement as suggested by Pasco et al. helps to overcome this issue. Based on the previous work of authors [10], the present work offers to minimize the efforts of full-field measurement of shear angle and uses only four dots towards central zone of the specimen to measure the shear angle (see Section 2.5).

In particular, this study offers a comparison between the intraply shear behavior of a selected thermoset prepreg and its constituent dry woven reinforcement fabric. This investigation is performed in an attempt to isolate the influence of thermoset resin on the overall inplane shear deformation behavior of a prepreg across a range of shear rates and temperatures that are industrial-process relevant. Further, the study discusses the suitability of the bias extension test as well as highlights the importance of the measurement of actual shear angles to obtain accurate intraply shear behavior of dry fabrics and prepregs at relatively elevated temperatures.

\section{Materials and methods}

\section{Materials}

One of the materials used for this study is a vinyl-based thermoset prepreg particularly developed to manufacturing press cured structural parts for the serial automotive industry. The second material considered is the dry fabric used in the same prepreg. The materials were provided by Solvay Heanor UK. Further details of the materials are as follows:

Solvalite 730: Carbon fiber vinyl prepreg with $2 \times 2$ twill weave fabric having an areal weight of $400 \mathrm{gsm}$ and a tow size of $12 \mathrm{k}$. The resin content of the prepreg is $38 \%$ by weight. The material thickness was measured as $0.4 \mathrm{~mm}$.

Figure 1 shows images of both the prepreg and dry fabric in the non-deformed state. The selected prepreg is ideally suited for high-rate manufacture of components using compression molding (press curing) process. The prepreg can be used to

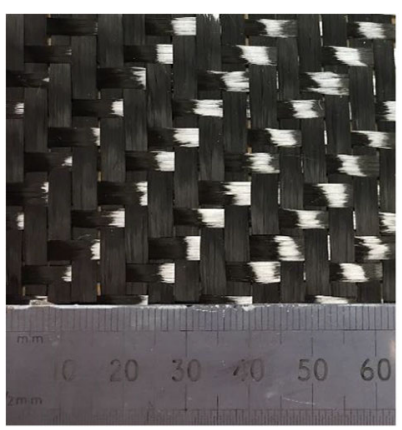

Dry Fabric

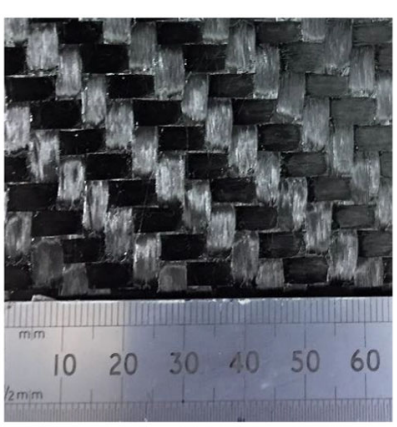

Prepreg
Fig. 1 The images of the rapid-cure prepreg (SolvaLite 730) and its constituent dry fabric 


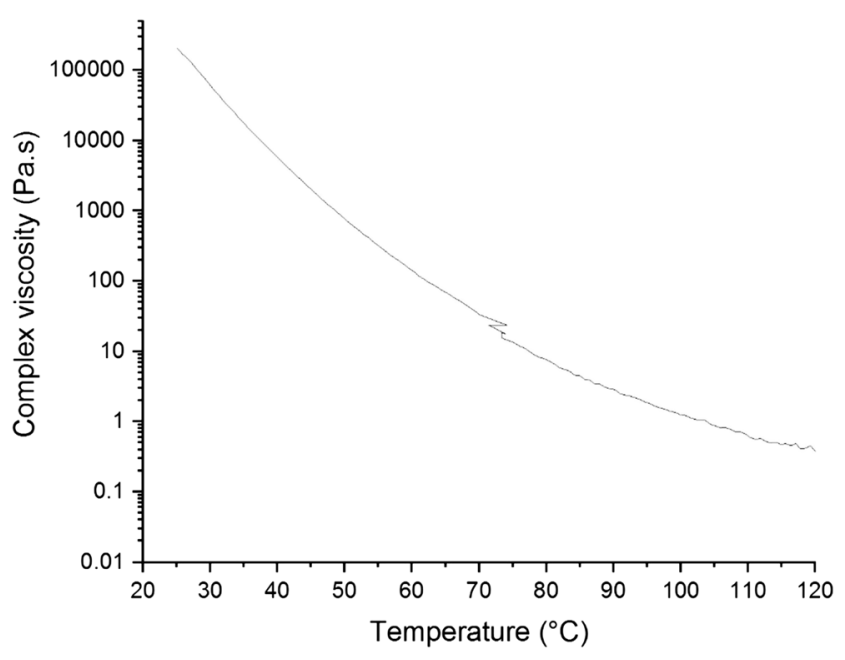

Fig. 2 Viscosity of the resin in the SolvaLite prepreg as a function of temperature

manufacture components with a total cycle time of $3 \mathrm{~min}$ using a recommended cure temperature of $150{ }^{\circ} \mathrm{C}$ within a pre-heated compression molding tools.

It is to be noted that the constituent dry reinforcement fabric of the prepreg material investigated here does not contain any binder material.

Figure 2 shows the viscosity of the vinyl-based resin in the prepreg material at different temperature. The viscosity vs temperature curve is plotted as a log-linear graph to demonstrate the change in viscosity at a relevant range of temperatures.

\section{Bias extension test}

The bias extension test is a de facto standard method to measure the in-plane intraply shear behavior for the fabrics and prepregs. The testing needs a careful cutting of the specimens, clamping in the specifically designed grips, selection of suitable test conditions preferably relevant to industrial process applications. The material geometry is of a rectangular shape where length of the specimen is typically double or more than its width to obtain a suitable state of shear i.e. three zones of 'pure shear', 'half shear' and 'undeformed' as shown in Fig. 3. The orientation of the fibers is maintained at $\pm 45^{\circ}$ to the loading direction in the undeformed configuration. The overall size of the bias extension specimen in these particular tests is $250 \mathrm{~mm}$ in length and $74 \mathrm{~mm}$ in width (effective gauge dimensions of ' $220 \mathrm{~mm} \times 74 \mathrm{~mm}$ '). Figure 3 shows the images of the bias extension specimens for the prepreg and dry fabric, in their undeformed and deformed configurations. In the bias extension test, the overall deformation of the specimens are shown to be equivalent in terms of undeformed, half-shear and pure-shear zones for the prepreg and its dry fabric.

The shear angle $\gamma$ (radians) is measured theoretically in the pure shear zone of the bias extension specimen [11] as:

$\gamma=90^{\circ}-2 \cdot \operatorname{acos}\left(\frac{L+\delta}{\sqrt{2} \times L}\right)$

Here $\delta$ is the change in length of the specimen and $\mathrm{L}=\mathrm{H}-$ $\mathrm{W}$; where $\mathrm{H}$ and $\mathrm{W}$ are the original height and width of the specimen, respectively.
Fig. 3 Bias extension testspecimens shown in their undeformed and deformed configurations for the prepreg and dry fabric

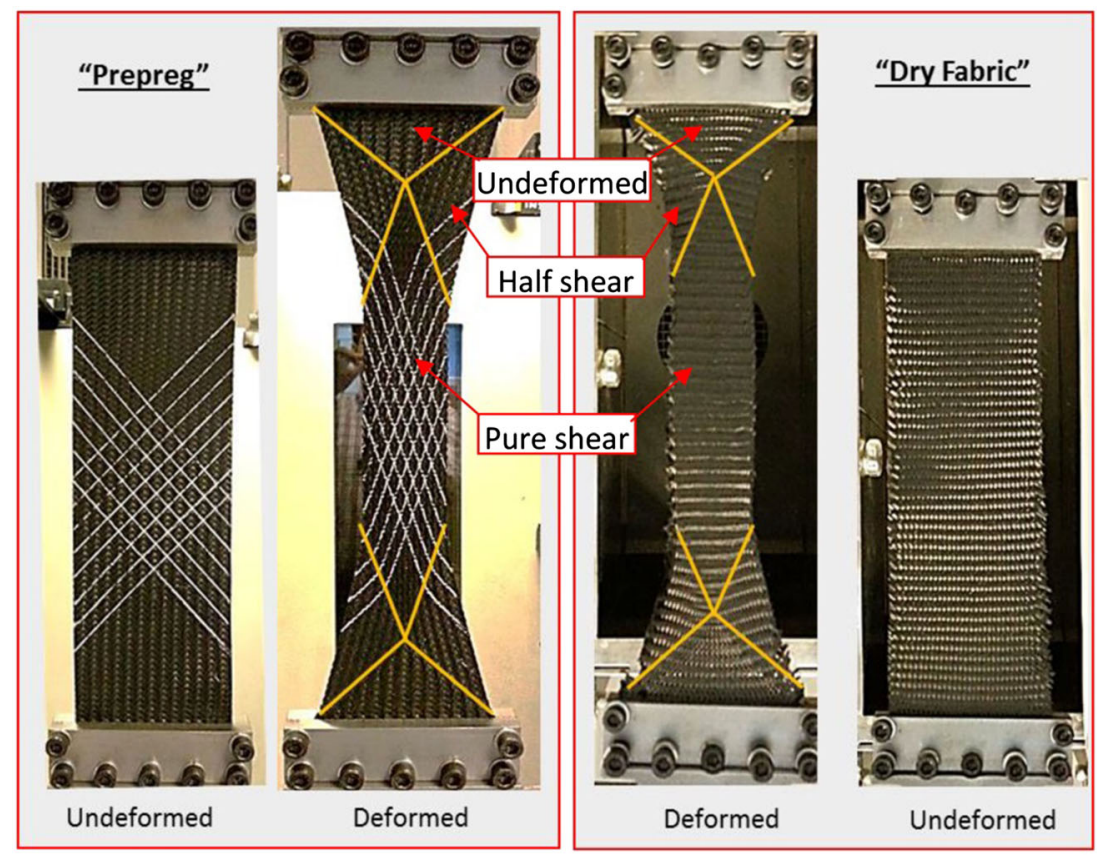


The applied force data from the bias extension tests can be converted into normalized shear force using an iterated process indicated in [11] as:

$F_{s h}(\gamma)=\frac{1}{(2 H-3 W) \cos \gamma}\left(\left(\frac{H}{W}-1\right) \cdot F \cdot\left(\cos \frac{\gamma}{2}-\sin \frac{\gamma}{2}\right)-W \cdot F_{s h}\left(\frac{\gamma}{2}\right) \cdot \cos \left(\frac{\gamma}{2}\right)\right)$

where $F_{s h}$ is the normalized value of the shear force (in $\mathrm{N} / \mathrm{mm})$.

Eq. (2) is a relationship between applied force, normalized shear force and shear angle in the pure and half shear zones of the bias extension specimen.

\section{Picture frame test}

Intraply shear behavior of prepregs as well as of dry fabrics with biaxial fibrous reinforcements can be characterized using picture frame tests. In the picture frame test, the sample is initially a cruciform-shaped. The specimen is held in the test-rig where the tows are aligned with the outer edges of the rig or oriented in the $\pm 45^{\circ}$ position to the loading direction. Figure 4 shows the undeformed and deformed geometries of the prepreg material. The picture frame test creates uniform shear for the entire specimen under investigation. Because the test is very sensitive to any misalignments in the orientation of fibers, extreme care is required when cutting the specimen as well as clamping it in the test-rig.

The effective specimen size used for the picture frame tests is ' $134 \mathrm{~mm} \times 134 \mathrm{~mm}$ '. The picture frame test-specimens were prepared using a Zund CNC cutter where fiber alignment errors arising due to manual cutting were reduced. The shear
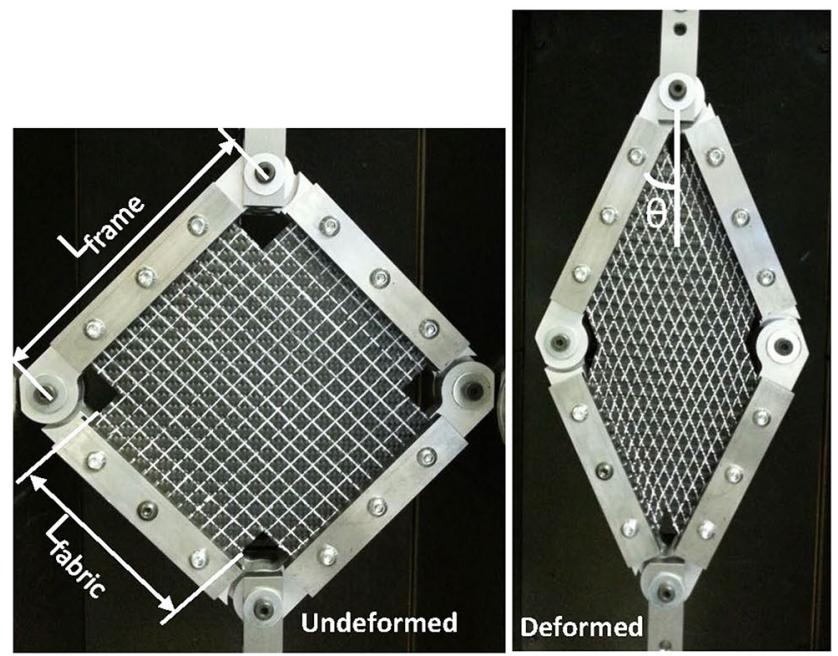

Fig. 4 Picture frame test-setup with prepreg material shown in its undeformed and deformed states where white grid-lines indicate the orientation of fibers angle, $\gamma$, can be calculated from the geometry of the picture frame as:

$\gamma=90^{\circ}-2 \cdot \operatorname{acos}\left(\frac{\sqrt{2} L_{\text {frame }}+d}{2 \times L_{\text {frame }}}\right)$

Where $L_{\text {frame }}$ is the side length of the picture frame jig between hinges, as indicated in Fig. 4 and $d$ is the extension applied on the frame.

The force data of picture frame tests can be normalized [11] using the relationship:

$F_{\text {normalized }}=F_{s} \cdot \frac{L_{\text {frame }}}{L_{\text {fabric }}^{2}}$

Where $F_{\text {normalized }}$ is the force normalized using an energy method, and $F_{S}$ is the shear force obtained such that:

$F_{s}=\frac{F}{2 \cos \theta}$

where $2 \theta$ is the angle of the frame (Fig. 4) and $\theta=\frac{\pi}{4}-\frac{\gamma}{2}$. The effective fabric length used for investigations is denoted by $L_{\text {fabric }}$.

Since the picture frame test provides a uniform shear strain field in the specimen, it is possible to interpret the forcedisplacement data in terms of shear stress versus shear strain. This provides an easy means to obtain the shear rigidity of the material [25]. The shear rigidity computed in the form of a polynomial expression is useful in order to numerically analyze the formability of composite plies of either a prepreg or a dry fabric [25-28].

The intraply tests were performed on Instron-5800R tensile and compression testing machine equipped using an environmental chamber with a load-cell capacity of $1 \mathrm{kN}$. For each test type and unique parameter set, at least three identical test repeats were carried out (depending on qualification of test concerning the level of variability) and the graphs are plotted as average of the test data considered qualified.

\section{Test conditions}

Table 1 summarizes the test conditions used for both the picture frame and bias extension methods using a range of temperature and shear rates. Both tests for the prepreg material are performed with equivalent shear rates of $0.94^{\circ} \mathrm{s}^{-1}$ and $4.9^{\circ} \mathrm{s}^{-1}$ at different temperature conditions of temperature (i.e. RT $\left(23{ }^{\circ} \mathrm{C}\right), 50^{\circ} \mathrm{C}$ and $\left.80^{\circ} \mathrm{C}\right)$. In contrast, the dry fabric is characterized using a single shear rate of $0.94^{\circ} \mathrm{s}^{-1}$ (an axial stretch rate of $1 \mathrm{~mm} / \mathrm{s}$ in the case of bias extension test) at room temperature only. This is because the dry fabric material behavior is shear rate and temperature independent, especially when there is no binder involved. 
Table 1 A summary of the experimental tests and parameters used for intraply shear characterization of the selected materials

\begin{tabular}{llllll}
\hline Material Type & \multicolumn{2}{l}{ Picture Frame test } & & \multicolumn{2}{l}{ Bias Extension test } \\
\cline { 2 - 3 } \cline { 5 - 6 } & $\begin{array}{l}\text { Temperature } \\
\left({ }^{\circ} \mathrm{C}\right)\end{array}$ & $\begin{array}{l}\text { Shear rate } \\
\left({ }^{\circ} \mathrm{s}^{-1}\right)\end{array}$ & & $\begin{array}{l}\text { Temperature } \\
\left({ }^{\circ} \mathrm{C}\right)\end{array}$ & $\begin{array}{l}\text { Shear rate } \\
\left({ }^{\circ} \mathrm{s}^{-1}\right)\end{array}$ \\
\hline Solvalite 730 prepreg & $23(\mathrm{RT}), 50,80$ & $0.94,4.9$ & & $23(\mathrm{RT}), 50,80$ & $0.94,4.9$ \\
Dry Fabric & $23(\mathrm{RT})$ & 0.94 & & $23(\mathrm{RT})$ & 0.94 \\
\hline
\end{tabular}

\section{Shear angle measurement}

Correct measurement of the intraply shear properties of composite reinforcements and prepregs is linked to the actual shear angle that develops during in-plane shear deformation of materials using the picture frame and bias extension tests. It has been shown by Pasco et al. [10] in the case of prepregs and Zhu et al. [13] in the case of dry fabrics that theoretical measurement of shear angle in bias extension tests based on PJN approach deviates from the actual shear angles after a certain stage of shear deformation. It is therefore important to employ a technique that correctly measures the actual shear angle, specifically during the bias extension tests in the so-called pure-shear zone. In contrast, the picture frame test does not require external shear angle measurement, because an overall uniform shear deformation exists within the acceptable limits over the entire specimen $[10,16,17]$. As a consequence, the determination of the material shear angle can be done using the rigid frame angle. For the bias extension tests in the current investigations, a video extensometer was used to track the axial and transverse displacements of the dots printed on the warp and weft tows of the specimen in the pure shear zone as shown in Fig. 5.
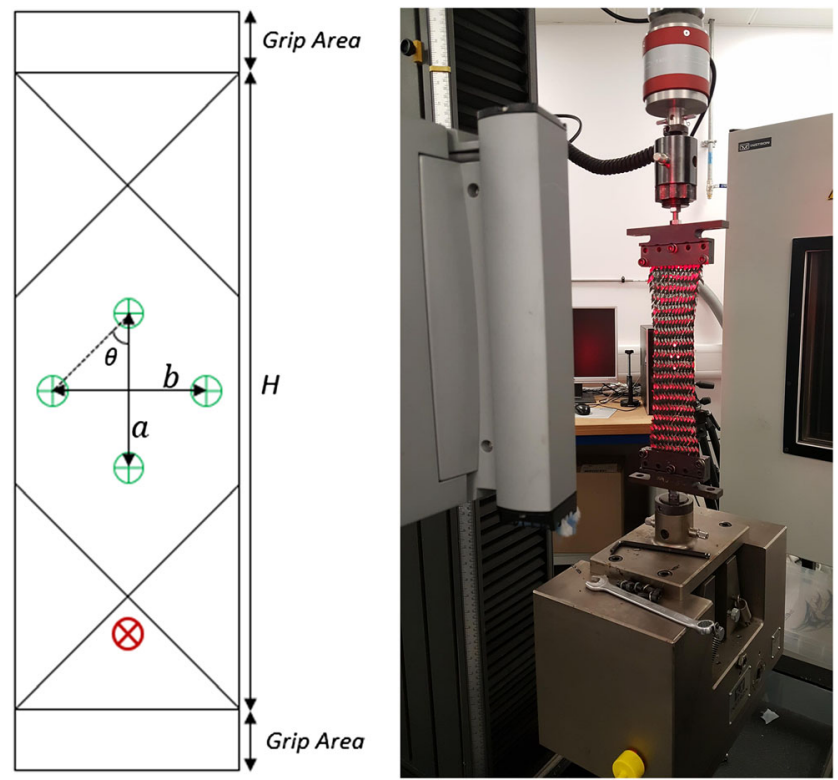

Fig. 5 Schematic and actual specimen with shear angle measurement in the pure shear zone of the bias extension test
The actual shear angle can be obtained using a simple trigonometric relationship:

$\gamma=\frac{\pi}{2}-2 * \tan ^{-1}\left(\frac{b}{a}\right)$

With: $\gamma$ is the measured shear angle, $a$ is the axial strain length and $b$ refers to the transverse strain length as shown in Fig. 5.

\section{Equivalent shear rate}

Because both the bias extension and picture frame tests are supposed to be used alternatively for measuring the shear behavior of biaxial reinforced materials, the data generated from two tests should be comparable. This necessitates using similar conditions of temperature and testing speed in the two test methods due to the temperature and shear-rate dependent viscosity of the prepreg material. Based on a recent test campaign by the authors presented in [10], the test speed has been converted into shear rate. Initially the shear rate obtained during a bias extension test was determined from the measured shear angle value and then based on this shear rate, the required crosshead speed for the picture frame test was calculated. Fig. 6 shows the measured shear angle values (in the pure shear zone) plotted against time for a bias extension test

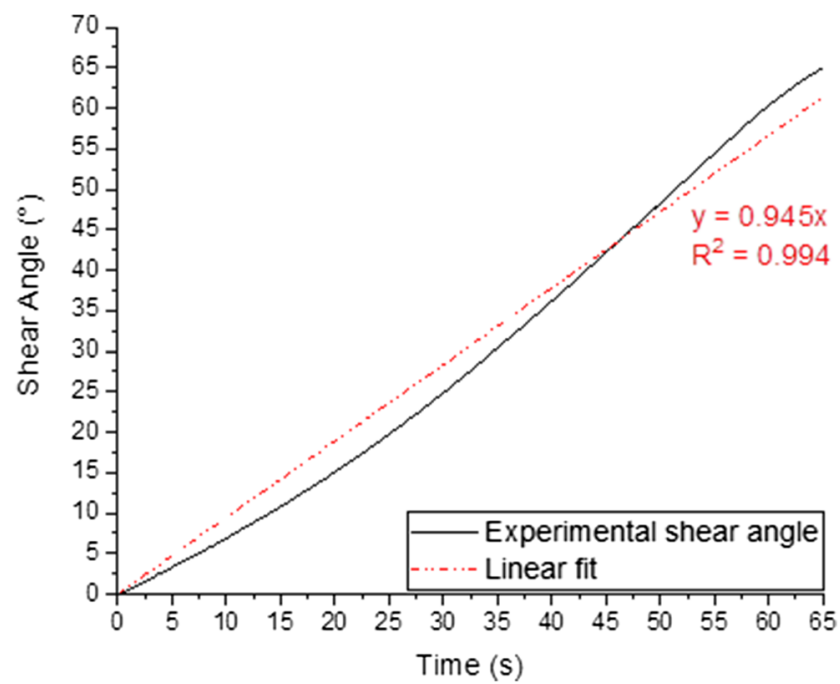

Fig. 6 Experimental evolution of the shear angle with time for a bias extension test performed with a crosshead speed of $1 \mathrm{~mm} / \mathrm{s}$ [10] 
performed with a crosshead speed of $1 \mathrm{~mm} / \mathrm{s}$. The shear angle varies in a quasi-linear trend with time, indicating a constant shear rate within the reinforcement during the test. The slope of the linear fit corresponds to the value of the shear rate in degrees per second $\left({ }^{\circ} \mathrm{s}^{-1}\right)$. In this case, a bias extension test performed with a crosshead speed of $1 \mathrm{~mm} / \mathrm{s}$ produces a shear rate within the material of approximately $0.94^{\circ} \mathrm{s}^{-1}$.

Based on this value, it is then possible to calculate the required crosshead speed needed during a picture frame test to produce a similar shear rate. It is shown in [29] that the angular shear rate during a picture frame test can be expressed as:

$\dot{\gamma}=\frac{d}{L_{p f} \sin \theta}=\frac{2 d}{\left(2 L_{p f}^{2}-2 \sqrt{2 L_{p f} d-d^{2}}\right)^{1 / 2}}$

Where $\dot{\gamma}$ is the shear rate, $\dot{d}$ and $d$ are the crosshead speed and displacement, respectively, and $L_{p f}$ is the side length of the frame. Rearranging Eq. (6), the required crosshead speed for a given angular shear rate can be expressed for any displacement of the picture frame such that:

$\dot{d}=\dot{\gamma} L_{p f} \sin \theta=\frac{\gamma^{\prime}\left(2 L_{p f}^{2}-2 \sqrt{2 L_{p f} d-d^{2}}\right)^{1 / 2}}{2}$

Figure 7 shows the required relationship between the crosshead speed and the crosshead displacement in order to obtain a constant shear rate of $0.94^{\circ} \mathrm{s}^{-1}$ during a picture frame test. It can be seen that this relationship is not linear, and slower crosshead speed are required as the test progresses in order to maintain a constant shear rate. This relationship was then programmed in the universal tensile testing machine, as a test speed based on an equation was not made possible using the machine software. Therefore, the function was discretized in small discrete steps of constant speed. The aforementioned

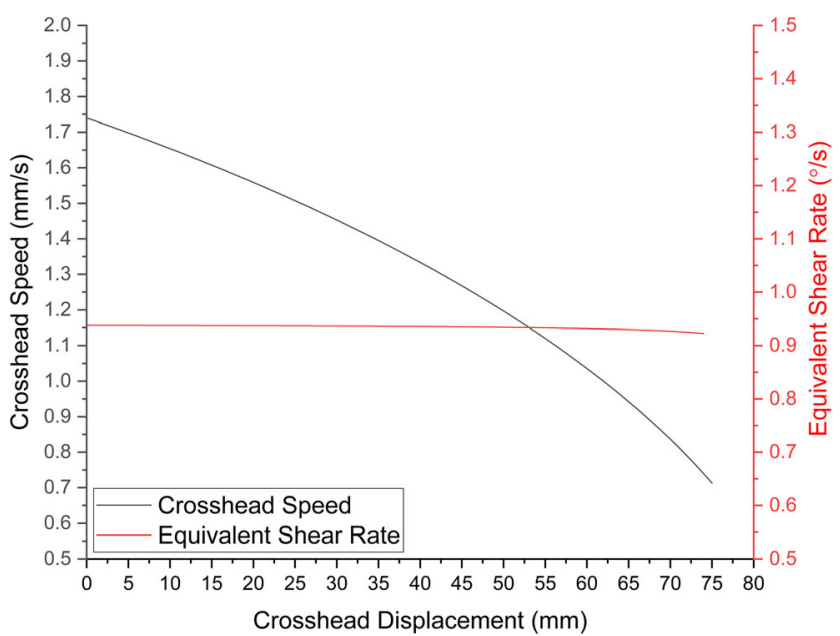

Fig. 7 The required relationship between the crosshead speed and the crosshead displacement for a picture frame test with an equivalent shear rate of $0.94^{\circ} \mathrm{s}^{-1}[10]$ procedure was then used in the case of bias extension test for an axial stretch rate of $5 \mathrm{~mm} / \mathrm{s}$ to get an equivalent shear rate of approximately $4.9^{\circ} \mathrm{s}^{-1}$ for the picture frame tests.

\section{Results and discussion}

A quantitative analysis of the intraply shear characterization of the selected prepreg and its dry fabric is presented together with the normalization of data from bias extension and picture frame tests.

\section{Bias extension test results}

The bias extension test results are presented as overall applied force $(\mathrm{N})$ versus shear angle $\left({ }^{\circ}\right)$ measured in the pure shear zone of the specimen for the woven prepreg and fabric (Fig. 8). The error bars represent one standard deviation on either side of the mean. Figure 8 shows the test results for the prepreg and its constituent dry fabric at different temperatures and strain rates. The results are presented in the log-linear form of force and shear angle to better approximate the magnitude of force at each stage of deformation.

\section{Temperature dependence}

The prepreg testing at $\mathrm{RT}, 50^{\circ} \mathrm{C}$ and $80{ }^{\circ} \mathrm{C}$ shows a continuous decrease in the magnitude of force with increasing temperature that can be observed in Fig. 8 from the overall trend of force vs shear angle curves. The most significant decrease occurs from RT to $50^{\circ} \mathrm{C}$. This is very clear when examining the applied force at $40^{\circ}$ shear angle, as shown in Fig. 9 (including the constituent dry fabric data as a comparator).

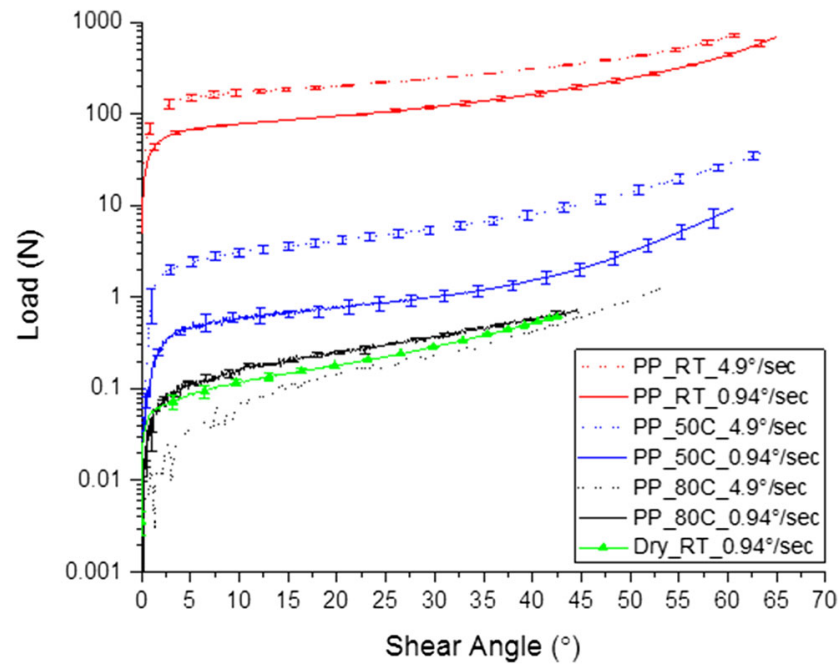

Fig. 8 The bias extension test results of force vs shear angle (log-linear) of the prepreg (PP) at different temperatures and its corresponding dry fabric (Dry) 


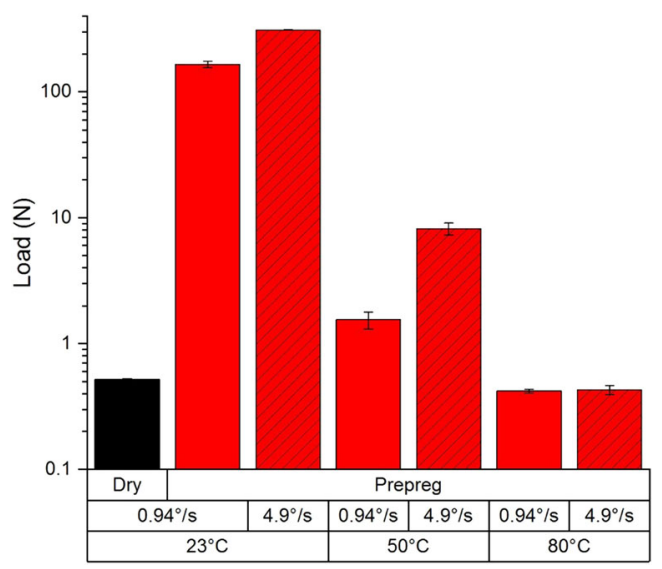

Fig. 9 Applied force measured at a shear angle $40^{\circ}$ shown for the selected shear rates and temperatures for the prepreg (PP) and its corresponding dry fabric (Dry) during bias extension tests

Considering the case of shear rate of $0.94^{\circ} \mathrm{s}^{-1}$, the applied force drops by $99 \%$ of the RT value when heating up to $50{ }^{\circ} \mathrm{C}$ and subsequently only by an additional $0.7 \%$ when heating to $80^{\circ} \mathrm{C}$. Similarly for the tests at a shear rate of $4.9^{\circ} \mathrm{s}^{-1}$, the load drops by $97 \%$ of the RT value when heating up to $50{ }^{\circ} \mathrm{C}$ and subsequently only by an additional $2.5 \%$ when heating to $80^{\circ} \mathrm{C}$. This behavior can be anticipated due to the change of viscosity of the resin as the temperature increases. Figure 2 shows the temperature-dependent viscous behavior of the prepreg resin where the viscosity of the vinyl-based resin drops significantly from RT to $50{ }^{\circ} \mathrm{C}$ but less so continuing up to $80^{\circ} \mathrm{C}$. The lower viscosity of the resin in the prepreg with increasing temperature decreases the shear stiffness of the prepreg. The elevated temperature processing of prepregs usually improves formability of the material and reduces the wrinkling defects [23].

\section{Strain-rate dependence}

Strain-rate dependency of intraply shear of the prepreg fabric can also be visualized in Fig. 8. The test-results are presented for the selected shear rates of $0.94^{\circ} \mathrm{s}^{-1}$ and $4.9^{\circ} \mathrm{s}^{-1}$. The force vs shear angle results can be interpreted considering the two shear rates for each category of temperature separately (i.e. RT, $50{ }^{\circ} \mathrm{C}$ and $80^{\circ} \mathrm{C}$ ) to observe the overall effect of strain-rate for the entire range of testing. Specifically, the difference in the force applied at RT at a shear angle of $40^{\circ}$ is presented in Fig. 9 for the shear rates of $0.94^{\circ} \mathrm{s}^{-1}$ and $4.9^{\circ} \mathrm{s}^{-1}$ respectively (i.e. an increase in the magnitude of force by $88 \%$ ). A similar trend of the increase in the applied force can be visualized in the case of temperature conditions of $50{ }^{\circ} \mathrm{C}$ and $80^{\circ} \mathrm{C}$. This difference in the shear force due to varying shear rates shows the strain-rate dependency of the viscous resin. It is known that an increasing strain rate will decrease the molecular mobility of the polymer chains by making the chains stiffer [30].

\section{Dry fabric comparator}

According to Fig. 8, the prepreg fabric results of intraply shear at $80{ }^{\circ} \mathrm{C}$ are of the similar order of magnitude to that of the dry fabric. This indicates the shear deformation behavior of the prepreg fabric at elevated temperatures $\left(\sim 80^{\circ} \mathrm{C}\right)$ is equivalent to its dry fabric reinforcement. Considering the intraply test results for the shear angle of $40^{\circ}$ (Fig. 9) as well as for the entire range of shear deformation (Fig. 8), there is only a difference of less than $10 \%$ for the applied force between the dry fabric and prepreg irrespective of the shear rate influence. These observations suggest that intraply shear dependent formability characteristics of a prepreg fabric converges to that of its corresponding dry constituent fabric at elevated temperatures.

\section{Shear angle comparator}

Figure 10 shows the results of actual shear angle measurement against theoretical shear angle in the pure shear zone of the bias extension test for the dry fabric and prepreg materials at the selected range of test temperatures (RT, $50{ }^{\circ} \mathrm{C}, 80^{\circ} \mathrm{C}$ ) using a crosshead speed of $1 \mathrm{~mm} / \mathrm{s}$. The actual shear angle results are measured using the method presented in Section 2.5; whereas the theoretical shear angles are calculated from Eq. (1) based on geometrical dimensions of the specimen and kinematics of the PJN approach.

It can be observed that the actual shear angle results tend to overlap with the curves of theoretical shear (up to about $55^{\circ}$ of shear angle) in the case of the prepreg material characterized at $\mathrm{RT}$ and $50^{\circ} \mathrm{C}$. However, the actual shear angle values for the dry fabric and prepreg at $80{ }^{\circ} \mathrm{C}$ start deviating from the theoretical ones at early stages of the shear deformation tests. In addition, it can be observed that under these conditions, the maximum shear

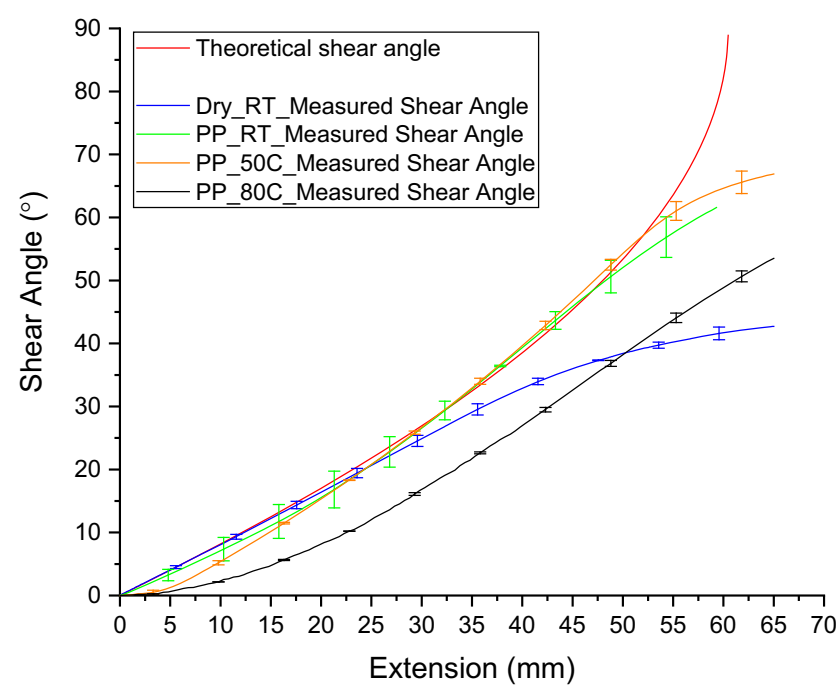

Fig. 10 Comparison of theoretical and actual shear angles measured in bias extension test, of the prepreg (PP) at different temperatures and dry fabric (Dry) at RT, at a shear rate of $0.94^{\circ} \mathrm{s}^{-1}$ 
angle obtained at the end of the bias extension test is significantly lower than that of the prepreg tested at RT and $50{ }^{\circ} \mathrm{C}$ (i.e. approximately $40^{\circ}$ for the dry fabric and $50^{\circ}$ for the prepreg tested at $80{ }^{\circ} \mathrm{C}$ against $65^{\circ}$ for the prepreg at RT). This difference, for the prepreg tested at $80^{\circ} \mathrm{C}$, can be attributed to the presence of the low viscosity resin at elevated temperature (or absence of a viscous medium in the case of dry fabric), which fails to provide a sufficient mechanical linkage at the crossovers between the warp and weft tows. Instead, the inter-tow slippage becomes a more dominant deformation mechanism.

\section{Picture frame test results}

The picture frame tests were also performed for both the prepreg and its constituent dry fabric. The test conditions used in picture frame tests were kept similar to the corresponding bias extension tests to compare the results from two methods. It is to be noted that the overall number of picture frame tests performed are more than double the number of tests considered qualified. The tests with lower level of applied force were considered qualified, as indicated in [10]. This is because the misalignment of tows generates spurious tensions in the fibers that ultimately influences the actual shear loads during characterization of the material [15].

Figure 11 shows the results of the influence of temperature and strain rate on the prepreg fabric with the picture frame testing. The results show a similar intraply shear behavior as it was observed in the bias extension testing. Overall, there is a continuous drop in the applied force with the increase of prepreg temperature (Fig. 11). It can also be observed that increase of shear rate generates higher loads in the case of prepreg testing for all selected states of temperatures. As mentioned in Section 2.3, the picture frame test typically produces inconsistent test results being highly sensitive to misalignment and pre-stressing issues. In

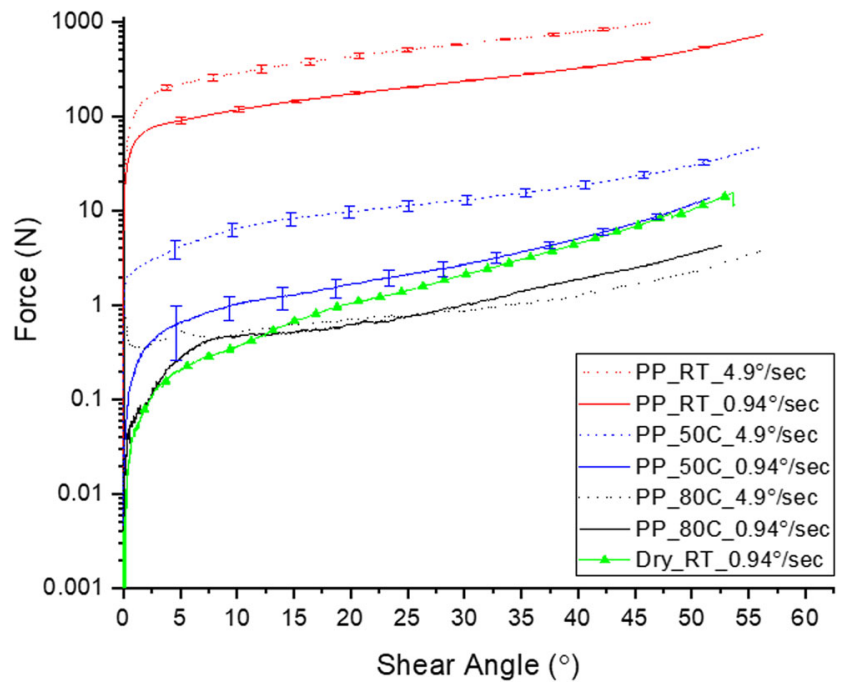

Fig. 11 The effect of temperature and shear rate on the prepreg (PP) obtained with picture frame tests with a selected range of temperatures and shear rates, and the comparison of results with the dry fabric (Dry) this context and to reduce the variability in the current testing campaign, the picture frame results with higher shear force were eliminated and the tests with lower force were considered qualified. Specifically, Fig. 12 shows the difference in level of the applied force observed at a shear angle of $40^{\circ}$ for different temperatures and strain rates. At a shear rate of $0.94^{\circ} \mathrm{s}^{-1}$, the difference in the force is quite insignificant for the elevated temperature testing of $50{ }^{\circ} \mathrm{C}$ and $80{ }^{\circ} \mathrm{C}$. However, the difference in the magnitude of force to shear deform the prepreg from RT to $50{ }^{\circ} \mathrm{C}$ is quite considerable, i.e. $320 \mathrm{~N}$ to $3.7 \mathrm{~N}$ respectively, at a shear angle of $40^{\circ}$ for the case of shear rate tests at $0.94^{\circ} \mathrm{s}^{-1}$ (Fig. 12).

According to Fig. 12, the prepreg fabric results of intraply shear at $80{ }^{\circ} \mathrm{C}$ are of the similar order of magnitude to that of the dry fabric. Again, this indicates the shear deformation behavior of the prepreg fabric at elevated temperatures $\left(\sim 80^{\circ} \mathrm{C}\right)$ is equivalent to its dry fabric reinforcement. The applied force is quite comparable between the dry fabric and prepreg at a shear angle of $40^{\circ}$, irrespective of the shear rate influence at $80{ }^{\circ} \mathrm{C}$. Again, these observations suggest that intraply shear dependent formability characteristics of a prepreg fabric converges to that of its corresponding dry constituent fabric at elevated temperatures.

\section{Normalization of bias extension and picture frame results}

As indicated in Section 2, the two tests of picture frame and bias extension are de facto standard tests for measuring intraply shear properties of biaxial reinforced materials, therefore, the results obtained from two tests should produce the same output ideally. Although the main difference is in the end-conditions of the tows of the specimen, yet it is worth comparing the results of the two tests for the same material, using Eqs. (2) and (4), to draw important conclusions on the suitability of the tests for any particular material. Further, the test conditions of shear rate and temperature should be same for both tests, especially when testing

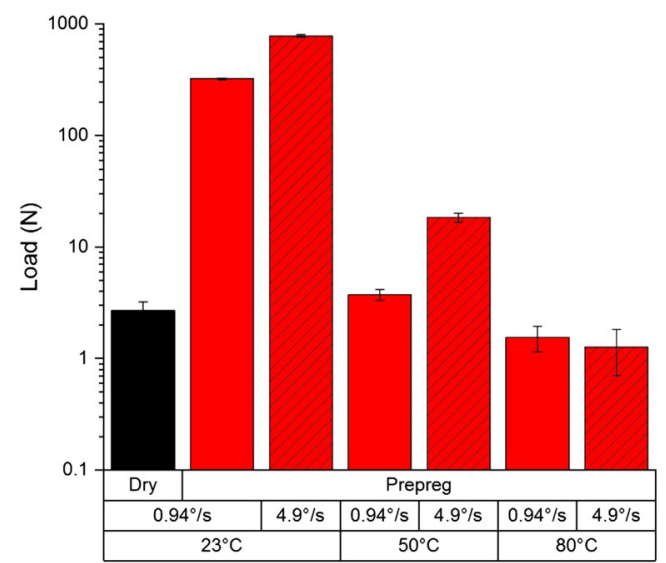

Fig. 12 The applied force at a shear angle $40^{\circ}$ for the selected shear rates and temperatures the prepreg (PP) and its corresponding dry fabric (Dry) during picture frame tests 


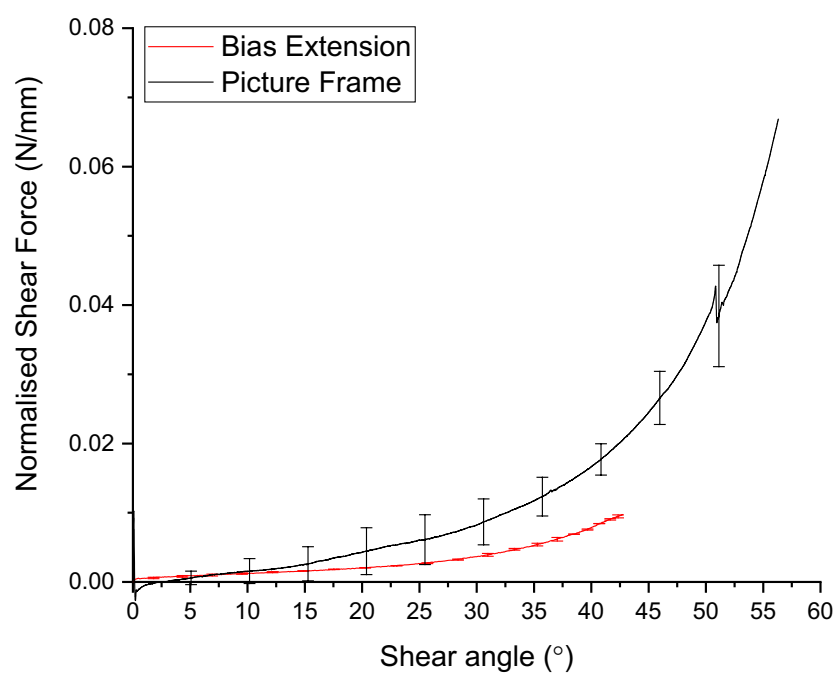

Fig. 14 Normalization of the picture frame and bias extension tests for the dry fabric at room temperature with a shear rate of $0.94^{\circ} \mathrm{s}^{-1}$

prepreg materials. It should noted that the normalization exercise is limited to the two test cases (i.e. for the prepreg using $50^{\circ} \mathrm{C}$ at $4.9^{\circ} \mathrm{s}^{-1}$; and for the dry fabric at $0.94^{\circ} \mathrm{s}^{-1}$ ).

Figure 13 shows a comparison of the intraply shear behavior of the prepreg determined after normalization of the data from the two tests. The data is presented in the form of normalized shear force $(\mathrm{N} / \mathrm{mm})$ vs measured shear angle $\left(^{\circ}\right)$ at $50{ }^{\circ} \mathrm{C}$ using an equivalent shear rate of $4.9^{\circ} \mathrm{s}^{-1}$ for the bias extension and picture frame tests. The normalized shear force obtained from both tests coincide very well throughout. However, the normalized shear force obtained from the two test methods in the case of dry fabric tends to deviate from one another as shown in Fig. 14.

This deviation can either be attributed to the difference in the boundary conditions of two test methods or due to the poor material integrity of the dry fabric and the lack of viscous resin. Based on the correlation of prepreg results presented in Fig. 13,

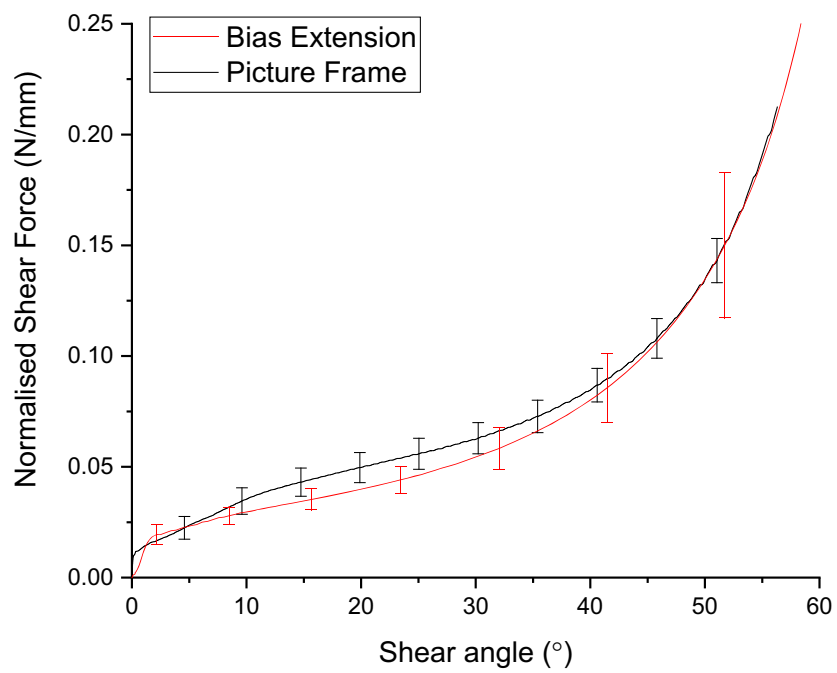

Fig. 13 Normalization of the picture frame and bias extension tests for the prepreg at $50{ }^{\circ} \mathrm{C}$ with a shear rate of $4.9^{\circ} \mathrm{s}^{-1}$ it can be argued that the deviation in the results in Fig. 14 is mainly dependent on the lack of integrity of the dry fabric tows (due to lack of any viscous resin) at the crossover points. Further, in the case of bias extension tests, the insufficient integrity of the material and free end conditions of the tows fail to provide the required kinematics. This results in significant intertow slippage that was also evident from the actual measurement of shear angles shown in Fig. 10. In contrast, the picture frame tests provide homogeneous deformation state due to rigid clamping of the specimen at the tow-ends. These observations suggest that, when testing material with a relatively poor integrity (as is the case for dry fabric and a prepreg at elevated temperature), the picture frame method might be more appropriate for correct measurement of the intraply shear properties.

\section{Conclusions}

This experimental investigation analyzes the intraply shear behavior of a rapid-cure thermoset prepreg and its dry constituent fabric. The two de facto test methods, of picture fame and bias extension, were used for measuring the shear deformability of the materials. Varying temperatures and deformation rates were used to study the shear deformation behavior of the candidate materials. The results indicate that the resin and the resin temperature have a significant influence on the force required to shear deform the prepreg fabric and thus affects the formability of the material, dependent upon the viscosity of resin.

It has been determined with this study that the intraply shear behavior of the rapid-cure thermoset prepreg and that of its constituent dry fabric reinforcements converges at moderately elevated temperatures. The actual measurement of shear angles in the case of bias extension tests, especially for the elevated temperature test conditions for the prepreg fabric, is important to determine the correct intraply shear behavior of the material. The actual measurement of shear angle also suggests the limitation of PJN approach (considered in preforming simulation) in the case of the prepreg testing at relatively higher temperatures); however for the dry fabric agreement with PJN is observed up to $\sim 30^{\circ}$. It can also be concluded that the bias extension test should be applied with care when characterizing intraply shear behavior of the rapid-cure prepreg at high temperatures as well as for the dry fabric where lack of sufficient inter-tow friction induces significant slippage. The picture frame test is recommended for the woven prepreg shear characterization at elevated temperatures; however, an extreme care is required to isolate the tests that generate spurious shear loads in the fibers due to small misalignment of the fabric tows. The picture frame test-data with lower range of shear force are required to be considered qualified.

Acknowledgements The work was funded by EPSRC through Researcher-in-Residence program and HVM CATAPULT (Ref. EP/ R513581/1). 


\section{Compliance with ethical standards}

\section{Conflict of interest for all authors None.}

Open Access This article is licensed under a Creative Commons Attribution 4.0 International License, which permits use, sharing, adaptation, distribution and reproduction in any medium or format, as long as you give appropriate credit to the original author(s) and the source, provide a link to the Creative Commons licence, and indicate if changes were made. The images or other third party material in this article are included in the article's Creative Commons licence, unless indicated otherwise in a credit line to the material. If material is not included in the article's Creative Commons licence and your intended use is not permitted by statutory regulation or exceeds the permitted use, you will need to obtain permission directly from the copyright holder. To view a copy of this licence, visit http://creativecommons.org/licenses/by/4.0/.

\section{References}

1. Pasco C and Kendall K (2016) Characterisation of the thermoset prepreg compression moulding process. In: SPE automotive and composites divisions - 16th annual automotive composites conference and exhibition, ACCE 2016, Novi, Michigan, USA, pp. 7-9

2. (2014) Composite developments drive auto industry forward. Reinf Plast 58:22-25

3. Mallick PK (2010) Thermoset-matrix composites for lightweight automotive structures. In: Materials, design and manufacturing for lightweight vehicles. Woodhead Publishing, pp. 208-231

4. Henning F, Kärger L, Dörr D, Schirmaier FJ et al (2019) Fast processing and continuous simulation of automotive structural composite components. Compos Sci Technol 171:261-279

5. Boisse $\mathrm{P}$, Aimène $\mathrm{Y}$, Dogui $\mathrm{A}$, Dridi $\mathrm{S}$, Gatouillat $\mathrm{S}$, Hamila $\mathrm{N}$, Aurangzeb Khan M, Mabrouki T, Morestin F, Vidal-Sallé E (2010) Hypoelastic, hyperelastic, discrete and semi-discrete approaches for textile composite reinforcement forming. Int J Mater Form 3(Suppl 2):1229. https://doi.org/10.1007/s12289-009-0664-9

6. Khan MA, Mabrouki T, Boisse P (2009) Numerical and experimental forming analysis of woven composites with double dome benchmark. Int J Mater Form 2(Suppl 1):201. https://doi.org/10.1007/ s12289-009-0549-y

7. Khan MA, Reynolds N, Williams G et al (2015) Processing of thermoset prepregs for high-volume applications and their numerical analysis using superimposed finite elements. Compos Struct 131:917-926

8. Harrison P, Alvarez MF, Anderson D (2018) Towards comprehensive characterisation and modelling of the forming and wrinkling mechanics of engineering fabrics. Int J Solids Struct 154:2-18

9. Boisse P. (2010) Simulations of woven composite reinforcement forming. Woven Fabric Engineering, Polona Dobnik Dubrovski, 978-953-307-194-7

10. Pasco C, Khan M, Kendall K (2019) A novel discrete method of shear angle measurement for in-plane shear properties of thermoset prepreg using a point-tracking algorithm. J Compos Mater 53: 2001-2013

11. Cao J, Akkerman R, Boisse P et al (2008) Characterization of mechanical behavior of woven fabrics: experimental methods and benchmark results. Compos Part A 39:1037-1053

12. Zhu B, Yu TX, Tao XM (2007) Large deformation and slippage mechanism of plain woven composite in bias extension. Composites Part A 38:1821-1828
13. Boisse P, Hamila N, Guzman-Maldonado E et al (2017) The biasextension test for the analysis of in-plane shear properties of textile composite reinforcements and prepregs: a review. Int J Mater Form 10:473-492

14. Lebrun G, Bureau MN, Denault J (2003) Evaluation of biasextension and picture frame test methods for the measurement of intraply shear properties of PP/glass commingled fabrics. Compos Struct 61:341-352

15. Launay J, Hivet G, Duong AV et al (2008) Experimental analysis of the influence of tensions on in plane shears behaviour of woven composite reinforcements. Compos Sci Technol 68:506-515

16. Lomov SV, Boisse P, Deluycker E et al (2008) Full-field strain measurements in textile deformability studies. Composites Part A 39:1232-1244

17. Krogh C, White KD, Sabato A, Sherwood JA (2019) Picture-frame testing of woven prepreg fabric: an investigation of sample geometry and shear angle acquisition. Int J Mater Form. https://doi.org/ 10.1007/s12289-019-01499-y

18. Wang P, Hamila N, Boisse P (2012) Intraply shearing characterization of thermoplastic composite materials in thermoforming processes. Key Eng Mater 504-506:243-248

19. Sun J, Gu Y, Min L et al (2012) Effect of forming temperature on the quality of hot diaphragm formed C-shaped thermosetting composite laminates. J Reinf Plast Compos 31:1074-1087

20. Mohan RP, Alshahrani H, Hojjati M (2016) Investigation of intraply shear behaviour of out-of-autoclave carbon/epoxy prepreg. J Compos Mater 50:4251-4268

21. Larberg YR, Akermo M (2011) On the interply friction of different generations of carbon/epoxy prepreg systems. Compos Part A 42: 1067-1074

22. Pasco C, Khan M, Gupta J et al (2019) Experimental investigation on interply friction properties of thermoset prepreg systems. J Compos Mater 53:227-243

23. Potter K (2002) In-plane and out-of-plane deformation properties of unidirectional preimpregnated reinforcement. Compos Part A 33: $1469-1477$

24. Larberg YR, Akermo M, Norrby M (2012) On the in-plane deformability of cross-plied unidirectional prepreg. J Compos Mater 46:929-939

25. Khan MA (2009) Numerical and experimental forming analysis of textile composite reinforcements based on a hypoelastic approach. $\mathrm{PhD}$ thesis, INSA de Lyon, France

26. Hamila N, Boisse P (2008) Simulations of textile composite reinforcement draping using a new semi-discrete three node finite element. Compos Part B 39:999-1010

27. Khan MA, Mabrouki T (2010) Vidal-Sallé, et al. numerical and experimental analyses of woven composite reinforcement forming using a Hypoelastic behaviour. Application to the double dome benchmark. J Mater Process Technol 210:378-388

28. Harrison P, Gomes R, Curado-Correia N (2013) Press forming a 0/ 90 cross-ply advanced thermoplastic composite using the doubledome benchmark geometry. Compos Part A 54:56-69

29. Clifford MJ and Long AC. Intra-ply shear of textile composites. In: proceedings of the $8^{\text {th }}$ international conference on fibre reinforced composites, 13-15 September 2000, Newcastle upon Tyne, United Kingdom

30. Richeton J, Ahzi S, Vecchio KS et al (2006) Influence of temperature and strain rate on the mechanical behavior of three amorphous polymers: characterization and modeling of the compressive yield stress. Int J Solids Struct 43:2318-2335

Publisher's note Springer Nature remains neutral with regard to jurisdictional claims in published maps and institutional affiliations. 